\title{
Postoperative Recurrence of Invasive Thymoma with Cold Agglutinin Disease and Autoimmune Hemolytic Anemia
}

\author{
Taro Yoneda, Hayato Koba, Kota Tanimura, Naohiko Ogawa, Satoshi Watanabe, \\ Johsuke Hara, Miki Abo, Takashi Sone, Hideharu Kimura and Kazuo Kasahara
}

\begin{abstract}
A 50-year-old man presented to our hospital in 1995. Invasive thymoma was diagnosed and extended thymectomy and left upper lobe partial resection were performed. In 2013, he complained of dyspnea. Chest computed tomography showed postoperative recurrence of invasive thymoma. Several chemotherapies were administered. Severe anemia and an increase in the total bilirubin level were observed with chemotherapies. In additional, an examination showed that the direct Coombs test was positive. Cold agglutinin was also high. We herein experienced a rare case of postoperative recurrence of invasive thymoma with cold agglutinin disease and autoimmune hemolytic anemia.
\end{abstract}

Key words: invasive thymoma, autoimmune hemolytic anemia, cold agglutinin disease

(Intern Med 55: 2685-2689, 2016)

(DOI: 10.2169/internalmedicine.55.6654)

\section{Introduction}

Thymoma is the most common tumor of the anterior mediastinum. At least $40 \%$ of patients with thymoma have parathymic syndrome (1). Although the mechanism of thymoma complicated with autoimmune hemolytic anemia remains unclear, these two conditions are often reported together. The frequency of concomitant autoimmune hemolytic anemia with thymoma is unclear, however, a previous study has reported 17 such cases (2).

In addition, there is no reported case of thymoma with cold agglutinin disease and autoimmune hemolytic anemia. Nevertheless, we experienced such a case. We herein describe the clinical course of our case and the management of the disease.

\section{Case Report}

A 50-year-old man presented to our hospital in 1995 and was diagnosed with invasive thymoma. Extended thymectomy and left upper lobe partial resection were performed. In 2003, computed tomography (CT) showed a tumor on the left cardiophrenic angle and the second thoracic vertebra. A tumor excision was performed. The pathological findings revealed an invasive thymoma (WHO classification type B3). Thereafter, the patient had unscheduled, periodic follow-up examinations at his own discretion.

In 2013, he complained of dyspnea and visited our hospital. Chest CT showed a left pleural tumor and left main bronchus occlusion. An accumulation of 18F-fluorodeoxyglucose was observed at the same locations by positron emission CT (Fig. 1). On admission, he did not have splenomegaly or libedo. The reason behind Raynaud's phenomenon was not clear as cyanosis of distal portion of the extremities was not observed by exposure to extremely cold conditions. His hemoglobin $(\mathrm{Hb})$ level was $15.5 \mathrm{~g} / \mathrm{dL}$. His white blood cell $(6,700$ cells $/ \mu \mathrm{L})$ and platelet $\left(20.4 \times 10^{4}\right.$ cells $/ \mu \mathrm{L}$ ) counts were normal. His total bilirubin (T-bil) level was $2.3 \mathrm{mg} / \mathrm{dL}$, and his cold agglutinin level was 1:16,384. The patient was initially suspected to have constitutional jaundice or cold agglutinin disease. Hemagglutination was confirmed at the time of blood testing, and cold agglutinin was also elevated (1:16,384). According to these findings, we diagnosed him with cold agglutinin disease. The patient was asymptomatic for anemia, therefore, a Coombs test was not performed. However, he was later diagnosed with postoperative recurrence of invasive thymoma. He received four 

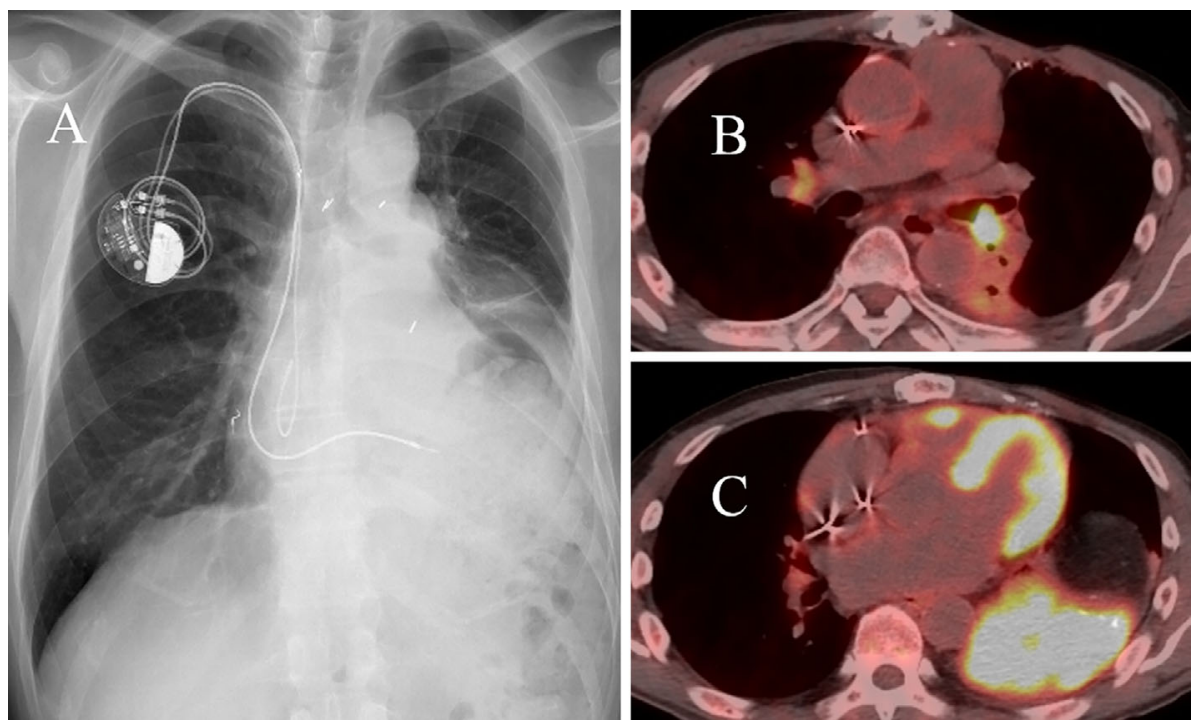

Figure 1. A chest X-ray (A) and positron emission computed tomography $(\mathrm{B}, \mathrm{C})$ on admission, showing a left pleural tumor and left main bronchus occlusion.

cycles of cisplatin and etoposide combination chemotherapy as the first-line treatment. Severe anemia and an increase in the T-bil level were subsequently observed. These changes were associated with chemotherapy. Although the first-line chemotherapy was effective, the tumor had increased in size in 10 months after treatment. As the second-line treatment, paclitaxel monotherapy was administered. A progression of anemia and a rapid increase in the T-bil level were observed. He was subsequently diagnosed with drug-induced autoimmune hemolytic anemia. When the direct Coombs test was initially performed, the red blood cells were positive for both antibodies and complement proteins bound to their surfaces. This finding supported the diagnosis of cold agglutinin disease. As the third-line treatment, gemcitabine monotherapy was administered. An increase in the T-bil level was again observed (Fig. 2). As the fourth-line treatment, pemetrexed monotherapy was administered. Because a severe decrease in $\mathrm{Hb}$ was observed after three cycles, he received a blood transfusion and was admitted into our hospital (Fig. 3). An examination on this admission showed reticulocytosis, a decrease in haptoglobin, and an increase in urinary urobilinogen. The Coombs test was performed once again and was positive for both antibodies and complement proteins bound to the surface of red blood cells. Cold agglutinin was also high at 1:8,192 (Table). To screen for anemia, upper and lower endoscopic examinations were performed. There were no gastrointestinal findings. A bone marrow biopsy was performed to exclude myeloid diseases and confirm the degree of myelosuppression by anticancer drugs. The bone marrow biopsy showed increased erythroblasts, no dysplasia, and no malignant cells (Fig. 4).

These findings were consistent with hemolytic anemia, achieving the diagnostic criteria of autoimmune hemolytic anemia set by the study group of the Japanese Ministry of Health, Labour and Welfare. The patient was therefore diagnosed with cold agglutinin disease and autoimmune hemo- lytic anemia with invasive thymoma. After admission, treatment with pemetrexed was immediately withdrawn, and the patient's anemia improved. At present, he is being followed up as an outpatient.

\section{Discussion}

In the present case, the cold agglutinin level in the patient was high at the start of first-line chemotherapy for invasive thymoma, and thus, he appeared to have cold agglutinin disease since the initial complaint of dyspnea when presenting at our hospital in 2013. Therefore, our patient was diagnosed with both postoperative recurrence of invasive thymoma and cold agglutinin disease. He received chemotherapy as a treatment for thymoma. Severe anemia and an increase in the T-bil level were observed. These changes were associated with chemotherapy, and he was additionally diagnosed with autoimmune hemolytic anemia. Both cold agglutinin disease and autoimmune hemolytic anemia are classified as primary or secondary diseases. Malignant lymphoma, mycoplasma infection, and Epstein-Barr virus were suggested as the primary diseases of secondary cold agglutinin disease (3). The coexistence of malignant lymphoma was excluded by a bone marrow biopsy, a biopsy of the tumor in the left main bronchus, and positron emission CT. However, it was difficult to determine whether cold agglutinin was a secondary disease. The patient's severe anemia worsened during several rounds of chemotherapy. Although he had cold agglutinin disease, his hematopoietic capacity made his hemoglobin level normal. The administration of anticancer drug therapy, however, resulted in myelosuppression, and his severe anemia subsequently worsened. In addition, following chemotherapy, the patient underwent a high number of episodes of anemia with increases in the bilirubin levels. Thus, the existence of secondary autoimmune hemolytic anemia was considered.Systemic erythematosus, lymphoproliferative 


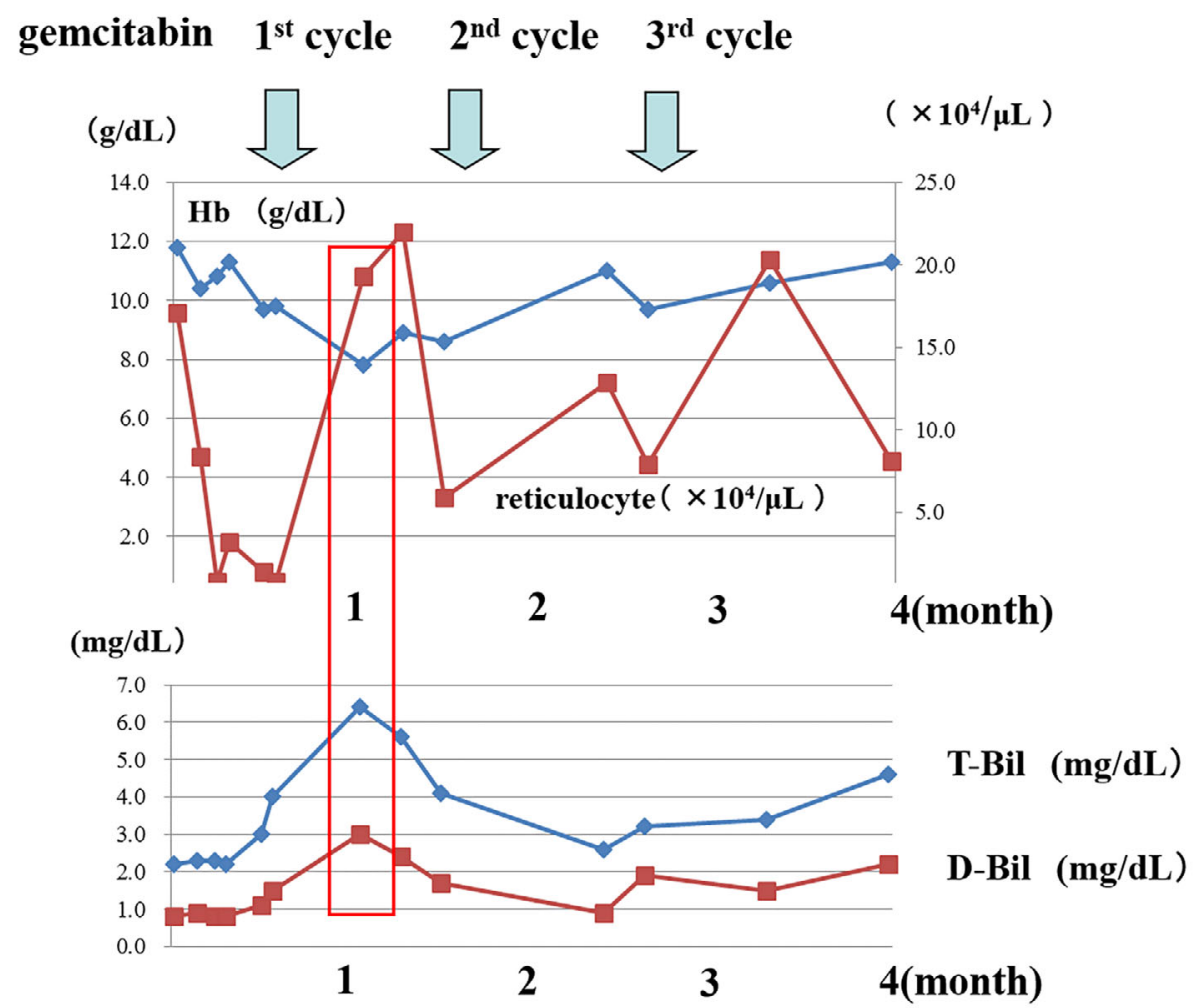

Figure 2. Course of hemoglobin, bilirubin, and reticulocyte on gemcitabine chemotherapy. The squared red line shows the period of severe anemia, reticulocytosis, and an increase in urinary urobilinogen.

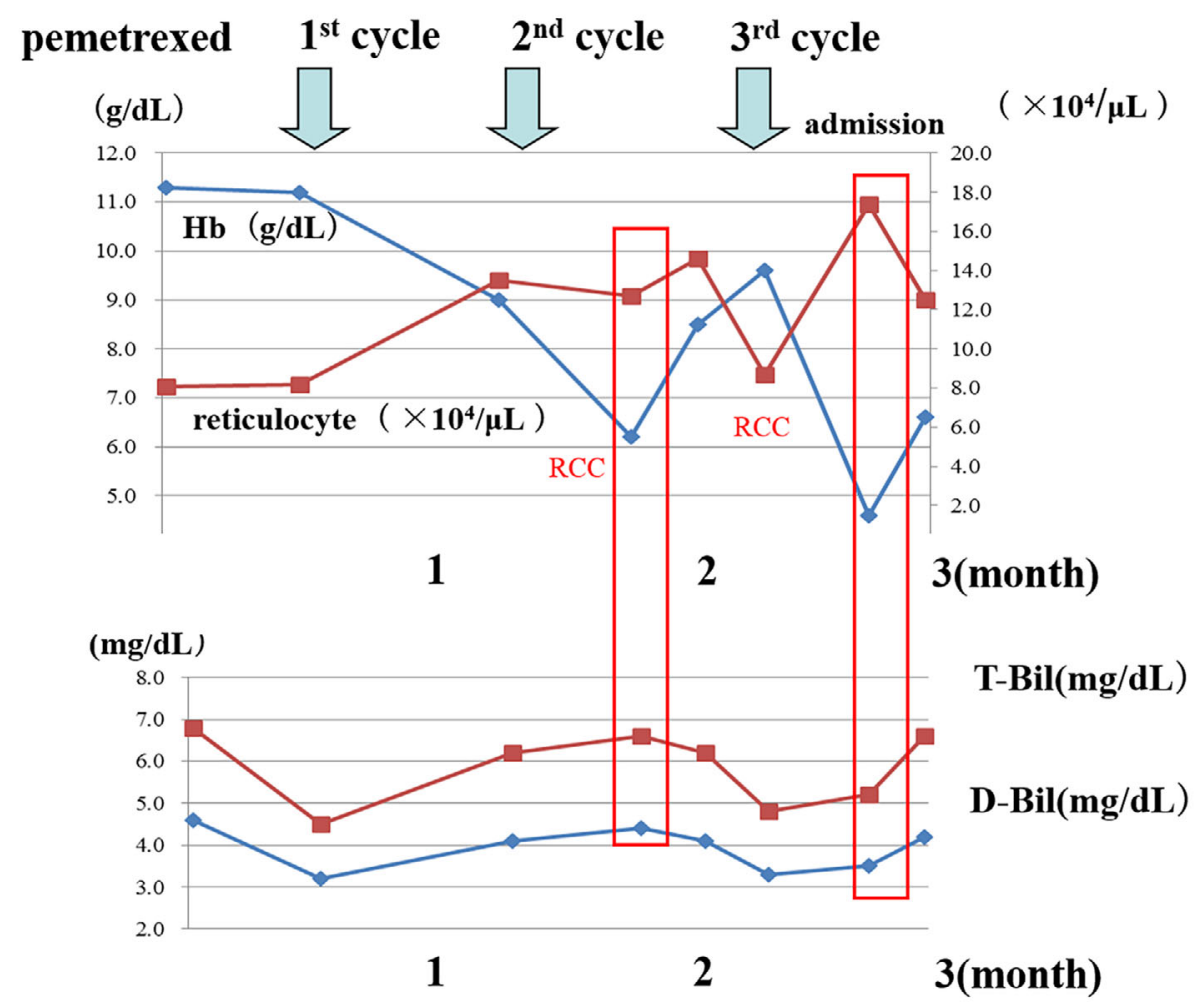

Figure 3. Course of hemoglobin, bilirubin, and reticulocyte on pemetrexed chemotherapy. The squared red line shows the period with severe anemia, reticulocytosis, and an increase in urinary urobilinogen. 
Table. Laboratory Data on Admission.

\begin{tabular}{|c|c|c|c|c|c|}
\hline WBC & 5,520 & $/ \mu \mathrm{L}$ & $\mathbf{F e}$ & 203 & $\mu g / d L$ \\
\hline Neut & 52.0 & $\%$ & TIBC & 267 & $\mu g / d L$ \\
\hline Eos & 0.5 & $\%$ & Feritin & 583 & ng/dL \\
\hline Lym & 37.0 & $\%$ & Reticulocyte & 17.4 & $\times 10^{4} / \mu \mathrm{L}$ \\
\hline Mono & & $\%$ & & & \\
\hline RBC & $148 \times 10^{4}$ & $/ \mu \mathbf{L}$ & Vitamin B12 & 935.0 & $\mathbf{p g} / \mathrm{mL}$ \\
\hline Hb & 4.8 & $g / d L$ & Folic acid & 18.8 & $\mathrm{ng} / \mathrm{mL}$ \\
\hline MCV & 98.6 & fl & EPO & 302.7 & $\mathbf{m U} / \mathbf{m L}$ \\
\hline МСН & 32.4 & pg & Haptoglobin & $<10$ & $\mathrm{mg} / \mathrm{dL}$ \\
\hline RDW & 20.9 & $\%$ & & & \\
\hline \multirow[t]{2}{*}{ Plt } & $10.3 \times 10^{4}$ & $/ \mu \mathbf{L}$ & Antiplatelet antibody & $(-)$ & \\
\hline & & & PA IgG & 104.0 & $\mathrm{ng} / 10^{7}$ cells \\
\hline TP & 6.5 & $\mathrm{~g} / \mathbf{d L}$ & Cold agglutinin & $1: 8,152$ & \\
\hline Alb & 3.8 & $\mathrm{~g} / \mathrm{dL}$ & ANA & $(-)$ & \\
\hline T-Bil & 3.6 & $\mathrm{mg} / \mathrm{dL}$ & & & \\
\hline D-Bil & 1.7 & $\mathrm{mg} / \mathrm{dL}$ & Direct Coombs test & $(+)$ & \\
\hline AST & 25 & $\mathbf{U} / \mathbf{L}$ & & & \\
\hline ALT & 16 & $\mathbf{U} / \mathbf{L}$ & Urine analysis & & \\
\hline LDH & 264 & $\mathbf{U} / \mathbf{L}$ & Urobilinogen & $(2+)$ & \\
\hline BUN & 27 & $\mathbf{U} / \mathbf{L}$ & Bilirubin & $(3+)$ & \\
\hline $\mathrm{Cr}$ & 1.30 & $\mathrm{mg} / \mathrm{dL}$ & Uric blood & $(-)$ & \\
\hline $\mathbf{N a}$ & 135 & $\mathrm{mEq} / \mathrm{L}$ & & & \\
\hline $\mathbf{K}$ & 4.5 & $\mathrm{mEq} / \mathrm{L}$ & & & \\
\hline Cl & 106 & $\mathrm{mEq} / \mathrm{L}$ & & & \\
\hline CRP & 0.3 & $\mathrm{mg} / \mathrm{dL}$ & & & \\
\hline
\end{tabular}

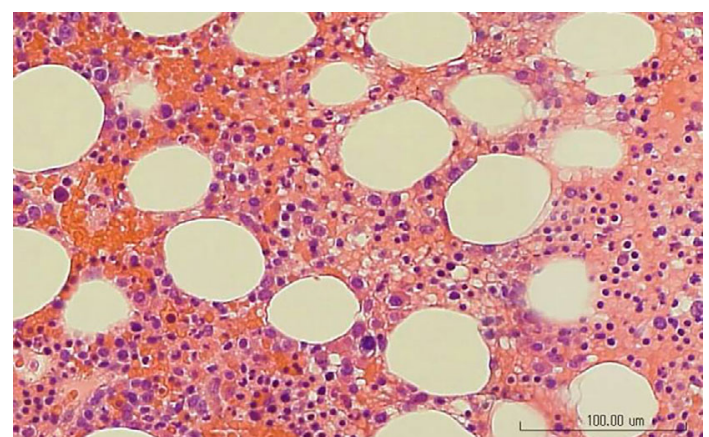

Figure 4. Pathological findings of bone marrow puncture and a bone marrow biopsy showing increased erythroblasts, no dysplasia, and no malignant cells.

disorder, acquired immunodeficiency syndrome, hypogammaglobulinemia, thymoma, pure red cell aplasia, and druginduced illness were considered as primary disease candidates for autoimmune hemolytic anemia (3).

In 2004, approximately 100 drug types were listed as causative agents of autoimmune hemolytic anemia (with a positive direct Coombs test) (4). The causative agents have changed over time. In the past, methyldopa and penicillin were reported. According to 126 reports between 1978 and 2004 , cefotetan $(62 \%)$, ceftriaxone $(10 \%), \beta$-lactamase inhibitors (8\%), and others (14\%) were reported (5). Regarding treatments related to anticancer drugs, cisplatin and carboplatin were reported $(6,7)$. In the present case, cisplatin was only used as a first-line treatment. Following second-, third-, and fourth-line chemotherapy, there were episodes of anemia with hemolytic anemia. This evidence is suggestive of the existence of drug-induced secondary autoimmune hemolytic anemia. As mentioned above, the final diagnosis of our case was acute drug-induced autoimmune hemolytic anemia and chronic idiopathic cold agglutinin disease.

Regarding acute drug-induced autoimmune hemolytic anemia, although cisplatin was initially suspected to have triggered this condition, other anticancer drugs also led to hemolysis. However, the degree of anemia and the T-bil level differed, in addition to the extent of illness elicited by the drugs. There was also a possibility that autoimmune hemolytic anemia existed since the initial presentation of dyspnea in 2013. However, its distinction from thymomarelated autoimmune hemolytic anemia was therefore difficult. The patient's anemia and T-bil levels improved following the withdrawal of anticancer drug administration. Stage 2 progression was classified according to the degree of clinical stratification. Regarding chronic idiopathic cold agglutinin disease, chronic passage was followed since first-line chemotherapy with high cold agglutinin. The causes were unclear as anemia was not initially observed. In addition, because the antibodies and complement proteins that are bound to the surface of red blood cells in the direct Coombs test were both positive, our case was classified as a mixedtype autoimmune hemolytic anemia with cold agglutinin disease and autoimmune hemolytic anemia. The frequency of such an occurrence ranges from $4.5-8.3 \%(8,9)$. Regarding the therapeutic approach, autoimmune hemolytic anemia can be cured with steroids. However, steroid therapy has a low impact on cold agglutinin disease. This difference in therapeutic effect is believed to be due to the difference in the proportion of self-participating antibodies (3).

Regarding the treatment strategy in the present case, although steroid treatment was not performed, severe anemia and the T-bil levels improved after the withdrawal of anticancer drug administration. When invasive thymoma re- 
lapses, we intend to start the patient on chemotherapy. Although high-dose steroid administration in chemotherapy may make the patient more vulnerable to infections, it is important to perform blood transfusion for serious anemia in such cases while the patient is still on chemotherapy.

In conclusion, we experienced a rare case of postoperative recurrence of invasive thymoma with cold agglutinin disease and autoimmune hemolytic anemia.

The authors state that they have no Conflict of Interest (COI).

\section{References}

1. Suzuki K, Inomata M, Shiraishi S, Hayashi R, Tobe K. Thymoma with aoutoimmune hemolytic anemia. Case Rep Oncol 7: 764-768, 2014.

2. De Keyzer K, Peeters P, Verhelst C, et al. Autoimmune haemolytic anemia assoziated with a thymoma: Case report and review of the literature. Acta Clinica Belgica 64: 447-451, 2009.

3. Kanekura Y, Kamazaki T, Kajii E, et al. Clinical practice guide- lines of autoimmune hemolytic anemia revised in 2013. Japan Intractable Diseases Information Center, 2015.

4. Petz LD, Garratty G. Immune hemolytic anemia. 2nd ed. Churchhill Livingstone, 2004: 261-317.

5. Arndt PA, Garratty G. The changing spectram of drug-induced immune hemolytic anemia. semin Hematol 42: 137-144, 2005.

6. Zeger G, Smith L, McQuiston D, Goldfinger D. Cisplatin-induced nonimmunologic adsorption of immunoglobin by red cells. Transfusion 28: 493-495, 1988.

7. Dacha S, Reddivari AK, Latta S, et al. Carboplatin induced fatal auto immune hemolytic anemia: First report case. World J Oncol 1: 173-175, 2010.

8. Kajii E, Miur Y, Ikomoto S. Characterization of autoantibodies in mixed-type autoimmune hemolytic anemia. Vox Sang 60: 45-52, 1991.

9. Shulman IA, Branch DR, Nelson JM, et al. Autoimmune hemolytic anemia with both cold and warm autoantibodies. JAMA 253: 1746-1748, 1985.

The Internal Medicine is an Open Access article distributed under the Creative Commons Attribution-NonCommercial-NoDerivatives 4.0 International License. To view the details of this license, please visit (https://creativecommons.org/licenses/ by-nc-nd/4.0/).

(C) 2016 The Japanese Society of Internal Medicine http://www.naika.or.jp/imonline/index.html 